Rev. Sociedad \& Equidad № 3, Enero de 2012.

\title{
Racionalidad, inmunidad, exposición: reflexiones sobre el caso de Luciano Pitronello
}

\author{
Rationality, immunity, exposure: Reflections
}

about the Luciano Pitronello case

$\begin{array}{ll}\text { Nombre: } & \text { Simón Pérez Seballos }\left(^{1}\right) \\ \text { Filiación: } & \text { Universidad de Chile } \\ \text { País: } & \text { Chile } \\ \text { Correo: } & \text { saimonperez@hotmail.com }\end{array}$

\section{RESUMEN}

El presente ensayo desarrolla elementos sobre Derechos Humanos, más allá de lógicas de tortura y violencia substancial a una dictadura. En particular, se focaliza en la exposición y la reacción que generó el supuesto atentado explosivo a una sucursal bancaria por parte del joven anarquista Luciano Pitronello, quien terminó con parte de su cuerpo quemado y con serias secuelas en su organismo. Para esto, se consideraron los comentarios escritos en el portal de noticias Emol y su bitácora personal. Estos, que cuestionaron su condición de humano con afirmaciones como "terrorista" o "parásito asqueroso", se pusieron en tensión con conceptos vinculados a la inmunidad y a quienes se consideran como "humanos paradigmáticos". La hipótesis planteada es que los medios no exponen los cuerpos en una lógica homogénea: algunos son inmunizados y otros expuestos por su potencial peligrosidad. Como principal conclusión, se estableció que los comentarios en torno a Pitronello exponen algunos esbozos de una racionalidad subyacente en ciertos integrantes de la sociedad chilena, poco observada, muy similar a la utilizada por los nazis, los criminales serbios o los hutus ruandeses. Por cierto, no es posible determinar si es algo generalizado, pero si bosqueja una problemática que debería observarse con mayor atención.

\section{ABSTRACT}

This paper develops elements on Human Rights, beyond the logic of torture and violence substantially to a dictatorship. In particular, it focuses on the exposure and the reaction that generated the alleged bombing of a bank by the young anarchist Luciano Pitronello, who finished with part of his body burned and with serious physical consequences. For this, it is considered the written comments on the news

\footnotetext{
${ }^{1}$ El autor es Licenciado en Comunicación Social, Periodista de la Universidad de Santiago de Chile. Actualmente cursa el Magíster en Comunicación Política en la Universidad de Chile. Sus líneas de investigación son Participación política y juventud.
} 


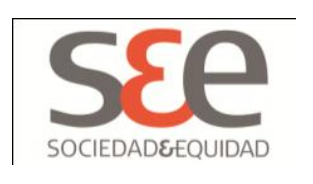

portal Emol and his personal blog. These, who questioned his human condition with statements like "terrorist" or "disgusting parasite", are set in tension with concepts related to immunity and who are considered "paradigmatic humans". The hypothesis is that the media do not expose the bodies in a homogeneous logic: some are immunized and others exposed for their potential danger. As the main conclusion, it was established that the comments about Pitronello expose some elements of a rationality behind certain members of Chilean society, little observed, very close to the Nazis, the Serbs criminal or Rwandan Hutus. Indeed, it is not possible to determine if it's widespread, but outlines a problem that should be watched more closely.

PALABRAS CLAVES: Inmunidad, Derechos Humanos, anarquismo, medios de comunicación.

KEYWORDS: Immunity, Human Rights, anarchism, mass media.

\section{Introducción}

Los Derechos Humanos suelen ser un tema recurrente dentro del discurso de los representantes de diversas colectividades políticas. Se apela a ellos en heterogéneas circunstancias, que transitan desde enfáticas defensas de la libertad individual, sobre todo relacionada con la irrestricta protección de la propiedad privada, hasta en discursos que buscan condenar y limitar prácticas con reminiscencias al autoritarismo dictatorial, asociado a formas de represión y de violencia, como en la actualidad pueden ser algunas de carácter policial.

La aceptación, por ejemplo, del Informe Valech por parte de la heterogeneidad del espectro político-partidista, como documento que expone y detalla las políticas de tortura cometida durante la dictadura militar, es una muestra de este último caso. "El reconocimiento de este triste capítulo de nuestra historia permite que todos los chilenos nos sintamos hoy parte de una misma comunidad y de un mismo destino. Este reconocimiento permite sentir que nuestras instituciones armadas nos pertenecen a todos los chilenos" (Comisión Nacional, 2004: 2); se puede leer en el prólogo de dicho documento.

Sin embargo, la utilización y defensa de los Derechos Humanos, por parte de los representantes políticos y, sobre todo, la reivindicación de estos por la propia ciudadanía, se difumina al momento de utilizarlos en la cotidianidad, más allá de esos espacios que se circunscriben dentro de las lógicas de la tortura y violencia política substancial a una dictadura -como es, en el caso chileno, asociada a la condena de las violaciones de Derechos Humanos en el periodo 1973-1990-. Ahí los Derechos Humanos dejan de tener presencia y, para la mayoría de la ciudadanía, sentido. No existen. 


\section{SEe}

Estos, muchas veces, son representados de forma nítida por los medios de comunicación, sobre todo la televisión. Hay varios ejemplos que se manifiestan en la cobertura policial y judicial de los medios de comunicación, quienes exponen sin ningún filtro a sujetos pertenecientes a estratos socioeconómicos determinados, a quienes se les graban sus rostros y se difunden sus nombres con total naturalidad cuando se inician procesos de formalización. A diferencia de sus antípodas de barrios acomodados, cuya identidad se difumina e incluso, muchas veces, se naturaliza la invisibilidad de sus cuerpos en tribunales, como algo propio del sistema judicial chileno.

En varias ocasiones, personas que han sido expuestas en todos los canales, diarios y radios, han sido declaradas inocentes en los días posteriores de iniciarse procesos de formalización, pese a declaraciones iniciales grandilocuentes desarrolladas por fiscales quienes, para los medios, parecen ser la fuente de mayor relevancia y credibilidad al momento de estructurar una nota informativa.

Un caso emblemático, no por su difusión sino por la exacerbación de esta lógica, fue la detención por error de Rosa del Carmen Farías Barrera, quien se encontraba con seis meses de embarazo y fue acusada de liderar una banda de asaltantes en el sector oriente (Águila, 2009). Su exposición en los medios fue total y sindicada como culpable de las imputaciones. En cambio, cuando fue declarada inocente, el nivel de cobertura no fue recíproco. Por cierto, no existió ningún tipo de autocrítica ni menos de acciones de reparación por parte de la policía o los medios de comunicación, más allá de unas disculpas públicas con escasa cobertura (Quezada, 2009).

En el presente ensayo, me centraré en realizar algunos esbozos sobre esta problemática, dirigiendo la mirada en torno a un caso en particular: la exposición -la puesta en escena de un cuerpo en particular- y la reacción que generó en la ciudadanía -limitando esta "reacción" a sus comentarios dentro de dos soportes digitales- del supuesto fallido atentado explosivo a una sucursal del Banco Santander por parte del ciudadano chileno, Luciano Pitronello, el pasado 1 de junio de 2011, quien terminó con gran parte de su cuerpo quemado y con pérdidas parciales de las manos y de la vista.

Creo que es más acertado comenzar a analizar el problema bajo esa categoría: "ciudadano", porque los epítetos de "anarquista", "violentista" o "delincuente", cargados de prejuicios y de condenas a priori, justamente refuerzan y ocultan el problema que voy a desarrollar y al cual me gustaría entregar algunos elementos de análisis.

La idea es comenzar esta discusión utilizando como eje el ensayo del intelectual pragmatista estadounidense Richard Rorty, "Derechos Humanos, racionalidad y sentimentalismo", en donde el autor pone en debate el problema 


\section{SEe \\ SOCIEDADEEQUIDAD}

vinculado a la noción que tienen las sociedades occidentales sobre los Derechos Humanos (él localiza su mirada en Europa y Estados Unidos), poniendo énfasis en la interrogante acerca de quiénes son los depositarios de estos derechos. 0 sea, se pregunta a quiénes consideramos humanos $\mathrm{y}$, por otra parte, a quiénes excluimos de dicha categoría, pese a que se apela, de forma reiterada, a nociones universalistas e incluyentes (Rorty, 1993).

Dicha pregunta, por cierto, fue planteada por el autor estadounidense en el contexto de la Guerra de los Balcanes, y es pertinente en el caso de Pitronello y en el escenario chileno en particular, donde se ha venido desarrollando una tendencia a considerar fuera del margen de "la gente como nosotros", que serían "los chilenos" como paradigma de derechos y deberes que oculta cualquier diferencia, a todo sujeto que antagonice los principios de la actual institucionalidad jurídico-política forjada en dictadura. Ya sean los mapuches, los ciudadanos pertenecientes a partidos políticos fuera del sistema binominal, los homosexuales, los inmigrantes y, por cierto, los jóvenes que adscriben al anarquismo como filosofía y práctica política.

Rorty plantea en su ensayo que el sentimentalismo (difusión de historias sentimentales que apelen a vivencias en común) puede "redimirnos" y así ampliar los márgenes de "la gente como nosotros". Este ensayo se inicia poniendo en duda esa premisa. La exposición de Pitronello quemándose en todos los canales de televisión, lejos de despertar algún sentimiento de identificación ante la desgracia de un "ser humano", solo reforzó un imaginario preconcebido en relación a los anarquistas, circunscribiéndolos en los márgenes de la irracionalidad y del terrorismo.

Junto a Rorty, también se tomarán algunos conceptos para desarrollar la segunda parte de la argumentación, contenidos en el libro La democracia inmunitaria de Alain Brossat, en relación a quiénes son finalmente los inmunes y los expuestos, en este caso, en los medios de comunicación.

La hipótesis que se plantea es que los medios no exponen los cuerpos en una lógica homogénea: hay algunos que son protegidos -muchas veces ocultados del imaginario televisivo y medial pero a la vez reivindicados en su ausencia-, inmunizados, regenerados. Y, por otra parte, cuerpos enfermos, peligrosos, cuya exposición reiterada demuestra su potencial peligrosidad para el resto del organismo (en este caso, la sociedad en su conjunto).

Existe un amplio margen de personas que quedan ajenas a estas protecciones que, como se señalaba anteriormente, pueden ser mapuches, anarquistas, feministas, entre otros. Brossat opone inmunizados a expuestos. Estos últimos, por ejemplo, pueden ser exhibidos quemándose en televisión y que no exista ninguna barrera que ponga en duda su presencia como objeto de entretenimiento televisivo, como es el caso de Pitronello. 


\section{SEe}

Para comenzar, se desarrollará el tipo de racionalidad presente en la reacción de una serie de comentarios escritos por ciudadanos chilenos al caso de Luciano Pitronello en diferentes soportes mediales. En este caso, su bitácora virtual personal y dos medios de comunicación online (específicamente, en los comentarios).

\section{Derechos humanos, racionalidad y... ¿crueldad?}

Lo que menos hay es sentimentalismo en frases como "parásito asqueroso", "basta de estas escorias de la sociedad", "un terrorista menos" o "me alegro que te haya explotado a ti esa bomba", que se pueden leer en la bitácora electrónica personal de Luciano Pitronello, titulada "Escritos de bohemia", escrita en un estilo informal y coloquial -propio de un joven de 17 años, ya que sus textos son del año 2005-, mucho antes de su supuesto fallido atentado explosivo, que terminó con el $30 \%$ de su cuerpo quemado, junto a la pérdida parcial de la vista y las manos.

Los comentarios no se quedaron en este tipo de calificativos. Muchos otros, recubiertos de groserías, analogías y burlas relacionadas con la pérdida de las manos, la ceguera producto de la explosión de la bomba y una especie de condena moral asociada en muchos casos a un catolicismo incipiente-, también pueden leerse aún en dicho sitio web.

El filósofo pragmatista Richard Rorty plantea que las personas que se parecen a "nosotros" son casos paradigmáticos de humanidad. En cambio, aquellos que son diferentes en su comportamiento y sus costumbres son, a lo sumo, limítrofes (Rorty, 1993: 2$)^{2}$. Rorty plantea una serie de distinciones entre el humano paradigmático y los casos limítrofes: humano/animal, adultos/niños (las personas ignorantes "son como los niños") y el hombre como sinónimo de humano -en desmedro de la mujer(Rorty, 1993: 3). Esta idea se fundamenta, de acuerdo al autor, en base a la tesis filosófica del fundacionalismo, que considera que los Derechos Humanos están incorporados a la naturaleza ahistórica de estos.

La respuesta de Richard Rorty ante los peligros de generar nociones limitadas que intentan presentarse como universales ("el humano paradigmático" en contrapartida del "parásito asqueroso", como califican a Pitronello), que sería el

\footnotetext{
${ }^{2}$ Rorty piensa en su ensayo "Derechos Humanos, racionalidad y sentimentalismo" en los actos de brutalidad de los serbios contra los bosnios en la guerra de Los Balcanes. Los primeros, al torturarlos, asesinarlos y violar a sus mujeres, no estarían actuando contra otros seres humanos dignos de respeto sino contra musulmanes. "No son inhumanos, sino que discriminan entre los verdaderos humanos y los pseudo-humanos" (1997, Rorty: 1). Lo mismo ocurría entre los cruzados y "los perros infieles", los musulmanes negros y "los diablos de ojos azules", los hutus contra los tutsis en Ruanda y también entre el chileno paradigmático y el anarquista peligroso, fuera del contrato social y ajeno a ese terreno común de "la gente como nosotros".
} 


\section{SEe}

desarrollo de historias sentimentales -por cierto, una solución algo débil y difícil de probar-, mediante una especie de expansión de experiencias comunes, en este caso ha fallado totalmente. Todo indicaría que la exposición de una persona quemándose en televisión debería llevar a una sensibilización por parte del receptor de dichas imágenes, sin embargo, el efecto es totalmente opuesto.

Este tipo de comentarios conllevan, en el presente ensayo, a plantear la siguiente pregunta: ¿Qué puede llevar a emitir este tipo de afirmaciones con ese nivel de rabia, agresividad y violencia? Sin duda, es una respuesta compleja, por lo que se entregarán algunos elementos de discusión preliminares al respecto.

Por un lado, está la estructuración de la noticia por parte de los medios de comunicación, quienes inmediatamente vincularon este hecho noticioso con el "Caso bombas"3 y la reiterada acción de asociar el anarquismo a un tipo de ideología política irracional y violentista - ya que es recurrente la homologación con los actos de violencia en manifestaciones públicas con el anarquismo en los medios de comunicación-.

Pero, junto a estos elementos, por cierto relevantes, también está presente un tipo de racionalidad subyacente, de la que se ocupa Rorty, que quizás no se observa con tanta nitidez pero que estructura este tipo de argumentaciones.

\section{Anarquista: ¿terrorista?}

Luciano Pitronello es un joven de 22 años, quien acaparó un gran número de planas y soportes noticiosos debido a la detonación en su cuerpo de un artefacto explosivo en una sede bancaria de Vicuña Mackenna con Victoria, en Santiago Centro. La totalidad de los medios de comunicación lo sindicaron como responsable del fallido atentado del 1 de junio de 2011, justificando sus afirmaciones en un video registrado por una cámara de seguridad del mencionado recinto bancario, donde se expone en detalle los segundos en que el joven se calcina poco a poco, hasta que es auxiliado por un taxista que pasaba por el lugar.

Su inocencia o culpabilidad deberá ser probada en un tribunal de justicia, de acuerdo a la legislación presente en Chile. Sin embargo, los medios no operan bajo esta lógica, realizando a priori juicios de valor, generando un clima de culpabilidad y de predisposición hacia la opinión pública, fundamentando esto en base a los argumentos de los fiscales, siendo condenado públicamente. No es relevante que el

\footnotetext{
3 La investigación, relacionada con la colocación de una serie de artefactos explosivos a lo largo de Santiago, liderada en casi la totalidad del proceso por el ex fiscal Alejandro Peña (que actualmente trabaja en el Ministerio del Interior), fue cuestionada por el titular del Octavo Juzgado de Garantía de Santiago, Luis Avilés, quien la calificó de "sociología barata" (Muñoz, 2011).
} 


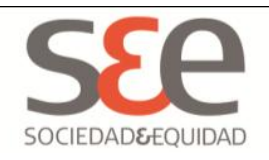

juicio no se haya iniciado ni menos considerar las declaraciones de la defensa. El principio de inocencia, en este caso, no es relevante.

En las crónicas periodísticas, sobre todo en los medios on-line, con la finalidad de fortalecer los contenidos informativos, se citó el blog personal ya mencionado de Pitronello, donde el joven escribió dos textos breves. El último, titulado "Protestas", fue redactado en un lenguaje adolescente y personal (con errores ortográficos que fueron omitidos en este ensayo), en donde anhela el desarrollo de una sociedad más activa y solidaria: "Por el hecho de ayudar podemos protestar, pero como todos sabemos nos hallamos en una sociedad dormida, con miedo a actuar porque puede salir dañada. ¿Por qué protesto si puedo perder? Preguntas como esas nos hacemos todos antes de dejar libres a las palabras. Creo que es ahí donde radica el problema: la falta de acción conjunta" (Escritos de Bohemia, 2005).

Casi seis años después de haber sido escrito, se pueden leer comentarios como "Dios castiga, pero no a palos", "nunca me río de las desgracias ajenas, pero tipos como tú no se les puede considerar personas", o "ahí quedó el perro sin manos y sin ojos". Llama la atención como los ejemplos expuestos por Rorty, en relación a los casos de "pseudo-humanidad" utilizados en su texto, relacionados con esos grupos que se alejan de "la gente como nosotros", se presentan de la misma forma y con el mismo nivel de crueldad en estas argumentaciones. Rorty lo plantea de la siguiente forma:

“Todos: los serbios, así como los moralistas, Jefferson y los musulmanes negros, emplean el término hombres para significar gente como nosotros. Todos creen que la línea divisoria entre los humanos y los animales no es simplemente la línea entre los bípedos sin plumas y todos los demás. (...) Antes bien, esta línea separa algunos bípedos sin plumas de otros: hay algunos animales que se pasean de forma humanoide. (...) Como lo dice Clifford Geertz en la Interpretación de las Culturas: las aseveraciones más importunas de los hombres respecto a su humanidad adoptan los acentos de un orgullo grupal" (Rorty, 1993: 2).

Además, dentro de estos comentarios, se aprecia una de las distinciones que realiza Rorty en relación a las formas en que los humanos "verdaderos" se separan de los "limítrofes", que no se encuentran funcionando en los mismos espacios de racionalidad. En este caso, la distinción utilizada de humano/animal aparece de forma recurrente. Sin embargo, su texto más comentado fue su primera entrada, que hasta la fecha tiene más de mil comentarios (con un porcentaje importante de insultos) que se titula “Ayudar”, en donde el joven plantea, a grandes rasgos, una 


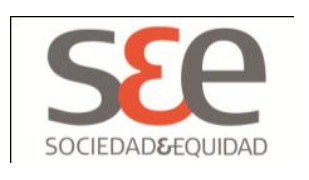

pregunta relacionada con los elementos que tenemos en común como seres humanos, que a su juicio sería la acción de ayudar al resto de las personas.

"Creo que vivimos en un mundo injusto, que nos creó para ver como peleamos y tratamos de ser mejor que nuestros semejantes. Algunos tuvieron la suerte de haber nacido en familias con dinero, otros con amor, y muchas más cosas. Pero, ¿qué nos diferencia? Creo que lo más práctico será responder, ¿qué nos hace comunes? Creo que es el deseo de mejorar, aunque no siempre podemos..." (Escritos de Bohemia, 2005). Además, él mismo agrega una reflexión en los comentarios de su texto, criticando al sistema capitalista y a las multinacionales que financiarían guerras. Por cierto, la "osadía” de buscar elementos en común planteada por Pitronello causó furibundos comentarios. Pocas veces se ven escritos con más de mil comentarios en algún blog en internet.

"Nosotros, y los que se parecen a nosotros, somos casos paradigmáticos de humanidad, pero aquellos que son demasiado diferentes de nosotros en su comportamiento o sus costumbres son, a lo sumo, casos limítrofes" (Rorty, 1993: 2). En este caso, Rorty tiene razón. Los chilenos, que escriben ese tipo de comentarios, están operando bajo una lógica similar, apelando a favor de una "verdadera humanidad" paradigmática versus una pseudo-humanidad. La analogía que utiliza Rorty, en relación a los filósofos morales, "quienes esperan limpiar al mundo del prejuicio y de la superstición” (Rorty, 1993: 2), es correcta. Actúan en el caso de Pitronello, pese a argumentar de una manera más burda y menos elaborada, con una matriz discursiva similar.

A todas luces, la solución que desarrolla Rorty, en relación a ampliar los márgenes de "la gente como nosotros", en base a la divulgación de historias tristes y sentimentales, que permitan visibilizar similitudes "cotidianas", más allá de diferencias étnicas o culturales, parecen ser insuficientes. Sobre todo, porque se sitúa dentro de una lógica eurocéntrica y occidental -él lo reconoce y lo explicita en su ensayo- donde justamente ellos, estarían en mejores condiciones para desarrollar este aspecto "sentimental", justificándose en una noción de progreso positivista y confiado en el desarrollo de la ciencia como potenciador del conocimiento humano y moral (desde una noción humanista). Además, junto con un supuesto mayor desarrollo de la cultura de los Derechos Humanos, herencia posterior a los horrores de los campos de concentración nazis.

Rorty recoge la idea de Anette Baier, focalizada en el abandono de la idea platónica de que poseemos un verdadero sí mismo, junto con el argumento kantiano de que es racional ser moral. Avanzar en esa dirección, según Baier, implicaría que tomemos la "confianza" y no la "obligación moral" como la noción moral fundamental. "Esta substitución implicaría que pensemos la difusión de la cultura de los derechos humanos no como una cuestión de llegar a ser más conscientes de los 


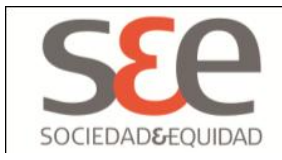

requisitos de la ley moral, sino más bien como lo que Baier llama un progreso de los sentimientos" (Rorty, 1993: 18).

Pese a los reparos que se pueden realizar al respecto, su diagnóstico es correcto. Apelar a un universalismo esencialista, justificado en la razón, es un engaño y una forma cómoda de tratar de comprender cómo se relacionan las nociones de Derechos Humanos. Este caso en particular de Pitronello, lo expone con nitidez. La idea del fundacionalismo de los Derechos Humanos, que considera que estos están incorporados en la naturaleza ahistórica del hombre, sería una idea caduca. Lo fundamental, para buscar una alternativa a esta noción totalizadora, sería el fortalecimiento de la cultura de Derechos Humanos.

En el caso particular de Pitronello, los ataques contra su persona se enmarcan, de acuerdo a las distinciones que realiza Rorty, dentro de la distinción categorial de humano/animal. Muchos de los comentarios critican y ponen en duda su condición humana de forma bastante explícita, resaltando su carácter "terrorista", su condición de "lacra", o sea, construyendo una argumentación que lo separa de los márgenes humanos del chileno "paradigmático" -impuesto mediante la mitología que se ha generado en torno a la estructura de la Hacienda en Chile-, ajeno al conflicto. De la misma forma como los mencionados hutus, serbios o musulmanes negros eran "la" humanidad dentro de sus propias culturas.

Este chileno paradigmático sigue estando presente dentro del país, pese a los cambios políticos, culturales y económicos, asociado a los márgenes de la ruralidad como un lugar central de la cultura, la identidad y el inconsciente colectivo del país. La historiadora María Rosaria Stabili, quien realizó un estudio sobre la aristocracia chilena mediante una serie de entrevistas en profundidad a personas que vivieron en haciendas durante gran parte de su vida, detalla cómo esta cultura propia de haciendas del Valle Central, recogida en una serie de trabajos literarios (Casa de campo de José Donoso, o La casa de los espíritus de Isabel Allende) sigue presente en el país mediante una forma de concebir y desarrollar las relaciones sociales.

Esto se vincula con una visión corporativista de la sociedad, donde cada parte del cuerpo está destinada a realizar funciones específicas y propias de acuerdo a sus capacidades (supuestamente naturales). Si se cambia o resquebraja su posición dentro del organismo, el cuerpo deja de funcionar correctamente. Por eso el inquilino es amigo del patrón cuando este es niño y pueden jugar fútbol y correr juntos por las praderas de las haciendas. Pero, cuando crecen, saben cuál es el rol dentro de esta concepción de la vida que cada uno desarrollará: uno mandará y el otro obedecerá. La historiadora lo puntualiza de la siguiente forma: "las relaciones entre ricos y pobres, entre patrones y subalternos -sean estos trabajadores agrícolas, obreros y empleados- continúan manteniendo un sello pre-moderno, paternalista y, al mismo tiempo, de desprecio en las confrontaciones de grupos subalternos, lejano a la idea de una igualdad del ciudadano frente a las leyes" (Stabili, 2003: 263). 


\section{SEe}

En este caso, toda esta noción de “chilenidad", justificada, tal como lo plantea Rorty, es una forma de racionalidad que pretende ser holista (esa es la trampa) pero que solo se limita a los márgenes de quienes lo enarbolan, como podrían haber sido los nazis, los serbios, los turcos otomanos -contra los armenios a principios del siglo XX-, los hutus contra los tutsis en Ruanda, quienes apelaban a una cierta pureza argumentativa, moral y racial que buscaba, justamente, ser omnipresente.

Los comentarios ya citados llaman la atención por lo tajante de sus afirmaciones y, sobre todo, por la lógica que opera detrás de estos para justificar dichas aseveraciones: Pitronello no es un ser humano (un chileno paradigmático); él es un anarquista. Por lo tanto, bajo esta lógica, es perfectamente legítimo condenar y estigmatizar sus acciones con la mayor crueldad posible, porque se encuentra fuera de este margen de "la gente como nosotros", de la misma forma como "los marxistas" eran el paradigma de maldad y antichilenidad durante la dictadura militar encabezada por Augusto Pinochet.

El anarquismo, en este caso, no está asociado a su desarrollo histórico en Chile, vinculado a protestas de emancipación y reivindicación de las luchas obreras, que tuvieron su auge a principios del siglo XX en diversas acciones e iniciativas con una considerable influencia social, como el rol que jugaron con la Federación Obrera Regional de Chile (FORCH), su labor "la huelga grande" de Tarapacá en 1907 y estando "en la vanguardia de la lucha por los derechos y emancipación de la mujer" (Grez, 2007: 147), como señala Sergio Grez, quien desarrolló un estudio desapasionado al respecto del primer auge del anarquismo en el país. Todos esos elementos son obviados, reduciéndolo a un enemigo burdo del sistema neoliberal.

A modo de reflexión, llama la atención que El Mercurio, en torno al anarquismo, haya realizado una nota en su sección "Tendencias y Mujer" el pasado 8 de julio, titulada "Cómo orientar a hijos anarquistas y rebeldes", en donde se entregan consejos para moderar conductas transgresoras de hijos adolescentes, lo que entrega pincelazos de cómo este medio comprende y aborda el anarquismo y las "disfuncionalidades" adolescentes. "Ser rebelde, no pescar, confrontar o transgredir las normas pueden ser actitudes típicas de la adolescencia, pero cuando esta conducta es sin respeto o pone en riesgo la vida de las personas hay que "tomar cartas en el asunto" (Vargas, 2011); puede leerse en el primer párrafo de la ilustrativa nota.

\section{Un flaite (sic) menos}

Sin embargo, el blog personal de Pitronello no fue el único espacio donde se difundieron estos comentarios en contra de un "no-humano", peligroso e irracional. Medios de comunicación pertenecientes a las dos principales cadenas periodísticas del país, como son el grupo Copesa y el grupo Edwards, presentan una cantidad importante de comentarios cargados de insultos y de afirmaciones ofensivas hasta el 


\section{SEe}

día de hoy en las noticias de sus portales on-line. Todo esto, pese a que existe un sistema de moderación en ambos portales, que sí suele eliminar o censurar comentarios de carácter político ajeno a sus principios. Cabría preguntarse si este tipo de calificativos están en concordancia con su línea editorial.

Uno de los más llamativos es el caso de Emol, portal que ha incorporado comentarios mediante perfiles de Facebook, por lo que el nivel de anonimato es ostensiblemente menor que en otras plataformas, aunque siempre puedan existir riesgos de suplantación. En el sitio, pese a que existe un sistema de moderación, hasta el día de hoy pueden leerse comentarios que se mofan de la situación, como "me alegro que le pase a personas de ese tipo", "espero que se muera ese infeliz", “justicia divina”, “un flaite (sic) menos”, entre otros (Águila, González, 2011).

La idea de rescatarlos no es apelar a una cierta moralidad idealizada o buscar un retorno a ciertos principios propios de ideologías totalitarias, sino exponer un fenómeno en ebullición, que demuestra una latente profundización de una lógica de rechazo y repugnancia hacia cualquier expresión que se aleje de los límites de lo que representan los "valores chilenos", asociados a esta exaltación de la ruralidad y los valores que se condensan en ese espacio social mencionados anteriormente.

Por lo mismo, cabe puntualizar aún más este problema, preguntándose qué tipo de lógica opera al momento de desarrollar ese tipo de afirmaciones. Richard Rorty recuerda que Platón "pensaba que el modo de hacer que las personas fuesen más amables las unas con las otras consistía en señalar lo que todas tienen en común: la racionalidad" (Rorty, 1993: 13). Sin embargo, el problema, tal como se desarrolla en ese texto, radica en torno a quién consideramos como depositario de esa racionalidad, como un "ser humano semejante, como un agente racional en el único sentido pertinente - en el sentido en el que la agentividad racional es sinónimo de pertenencia a nuestra comunidad moral-" (Rorty, 1993: 14). El error para Rorty es que la idea de "reeducar" a las personas, invocando a un poder superior -el poder de la razón- hizo que la filosofía partiera con el pie equivocado, volcando los esfuerzos en la figura infrecuente del psicópata y no de un caso mucho más común: "la persona cuyo tratamiento de una gama más bien estrecha de bípedos sin plumas es moralmente impecable, pero quien permanece indiferente frente al sufrimiento de los que caen por fuera de esa gama, aquellos que él o ella considera como pseudohumanos" (Rorty, 1993: 13).

Claramente, los ciudadanos que escribieron en la bitácora del Pitronello y comentaron la noticia del accidente en el sitio de El Mercurio Online (Emol) no lo consideran como un igual, sino como alguien inferior que se opone e incluso amenaza sus propias identidades y seguridades. Es el equivalente al musulmán (bosnio) mutilado que describe David Rieff al iniciar el texto del citado autor pragmatista. 


\section{SEe}

En relación a este punto, Naomi Klein (2007) entrega algunos elementos que podrían explicar esta racionalidad subyacente en este tipo de comentarios: Chile tiene un "shock" moderno "fundacional" no abordado con toda la fuerza necesaria, que ha sido el principal articulador de la institucionalidad que dirige los destinos del país. Me refiero a las políticas de tortura y desaparición de miles de ciudadanos chilenos, que fueron el preámbulo para generar todo el modelo neoliberal chileno y que fueron consustanciales para su institucionalización. Es cierto que se han realizado políticas de reparación a las víctimas (como el Informe Valech mencionado en la introducción), pero este dolor, sufrimiento y pérdida de miles de chilenos no está relacionado de forma explícita con el proyecto ideológico establecido durante la dictadura militar.

Puede que, a modo de hipótesis, esta racionalidad presente en esta verborrea contra Pitronello sea heredera de la misma racionalidad que legitimó y aún defiende en base a sus obras de carácter permanente, más allá del terror dictatorial, toda la estructura del proyecto ideológico neoliberal urdido por los Chicago Boys, los gremialistas y las Fuerzas Armadas que adscribieron estos axiomas. Cabe recordar que Chile es considerado como el primer "experimento" de este modelo impuesto mediante diversos "shocks" -en base a la terminología de Naomi Klein- en países tan diversos como Rusia, China, Sri Lanka o Sudáfrica (Klein, 2007).

Naomi Klein pone a Chile como el primer ejemplo de implantación de un sistema neoliberal, donde la liberación de la economía y la privatización de los servicios públicos eran el pilar de una sociedad a construir, pero puesto en práctica en base al shock paralizante de la tortura y la muerte, en donde los responsables y beneficiarios quedaron "inmunes". "La primera aventura de los Chicago Boys en la década de 1970 debió haber servido de aviso a la humanidad: sus ideas eran peligrosas. Al no hacer responsable a la ideología de los crímenes cometidos en su primer laboratorio, se dio inmunidad a esta subcultura de ideólogos impenitentes y se les liberó para que recorrieran el mundo en busca de sus próxima conquista" (Klein, 2007: 173).

La autora agrega que en la actualidad esta misma lógica sigue presente en el orbe, ya que sigue propagándose el mismo mito fundacional y los ingredientes de violencia militar, tortura y desapariciones, en donde no se avizora "ninguna relación entre el objetivo de conseguir nuevos mercados libres y la necesidad de utilizar la violencia para lograrlo" (Klein, 2007: 173). Este tipo de violencia queda invisibilizada, pero la ejecutada por un anarquista acapara todas las miradas.

\section{Inmunidad vs exposición}

Otro aspecto de esta problemática, es el tipo de cobertura informativa que han utilizado algunos medios de comunicación en esta noticia, más allá de la racionalidad subyacente en los comentarios utilizada en estos para desarrollar sus 


\section{s\&e \\ SOCIEDADEEQUIDAD}

argumentaciones. Esta radicaría en el tipo de exposición de los cuerpos en dichos contenidos periodísticos.

Lo que se aprecia, sobre todo en este tipo de coberturas informativas, es la tendencia a inmunizar, por un lado, a un grupo de la población chilena dentro de las notas informativas $y$, por otro lado, a exponer de forma explícita a otro sector de la población, asociándolo a una condición de enfermedad, fragilidad y de daño contra el resto del grupo. 0 sea, su exaltación en los medios de comunicación constituye una especie de advertencia hacia donde, como sociedad, no deberíamos caminar. Es la tendencia que se aprecia en el caso de Pitronello.

Tomando en cuenta este planteamiento, cabe mencionar la distinción que realiza Alain Brossat dentro de las democracias occidentales entre "inmunizados" y "expuestos", en donde se realiza un proceso de reducción a la condición de vida desnuda o abandono a su propia suerte a aquellas personas a las que un Estado ya no les garantiza la Constitución en tanto personas humanas (Brossat, 2008: 32).

Brossat cita a Hannah Arendt, recordando su trabajo en torno al totalitarismo, ya que considera que sus temores siguen vigentes en las sociedades democráticas post-totalitarias, donde esta distinción entre inmunizados y expuestos se intensifica. "En relación a los inmunizados, las garantías se vinculan al derecho, pero también a la noción de una disciplina de los cuerpos, de sus justas reparticiones, reglas higiénicas y sanitarias (...), esta doble red se establece sobre un fondo de sensibilidad que enuncian lo que es correcto e incorrecto, lo ilustrado y lo retrógrado, lo aceptable y lo intolerable o lo escandaloso" (Brossat, 2008: 34). Es decir, esta serie de seguridades biopolíticas de resguardo del cuerpo van acompañadas no solo de un marco jurídico de resguardo y protección, sino también de una serie de sensibilidades asociadas a estas protecciones, que establecen qué es lo que se debe tolerar y a la vez, qué es lo que se debe condenar y, por ende, alejarse en busca de esa pureza corporal.

Alain Brossat señala que "el régimen mismo del ser comunitario es rigurosamente antagónico a la aspiración inmunitaria" (Brossat, 2008: 14). Más adelante, profundizando esta idea, el autor señala que "la intensificación del proceso de inmunización se acompaña de un proceso de dualización que, al mismo tiempo, atraviesa las sociedades occidentales y acrecienta la separación entre ésta y otras que quedan separadas de la corriente" (Brossat, 2008: 30). Por un lado, toda la emocionalidad y la tristeza en torno al atentado de las torres gemelas, pero por el otro, la indiferencia en torno a las hambrunas en África o a las guerras en Medio Oriente. Brossat lo resume de la siguiente manera: "mientras más fuertes son las garantías de inmunización para los beneficiarios de estas evoluciones, más draconianas son las condiciones de abandono o de rechazo a las que están destinados quienes no forman parte" (Brossat, 2008: 30). 


\section{SEe}

Cabe señalar que dentro de este proceso, no solo la ley o el derecho contribuyen a mantener y propiciar esta estructuración democrática: los medios de comunicación juegan un papel importante en esto. Incluso, un deporte que puede ser considerado inofensivo, como es el caso del fútbol, puede constituir un ejemplo de esta lógica inmunitaria, ya que puede desarrollar de forma explícita simulacros de guerra civil, pero en condiciones de normatividad inmunitaria (Brossat, 2008: 38).

Para Brossat, mientras más se desarrolla la ideología comunicacional, "este habermasianismo de supermercado comunicacional mantenido principalmente por los medios de comunicación, las grandes marcas y la clase política de los países ricos (...), y más implícitamente (y quizás sobre todo) son validados estos dispositivos de alejamiento y de separación de los individuos (entre ellos) y de los grupos" (Brossat, 2008: 43).

A continuación, se esbozarán algunos elementos de este planteamiento con algunos ejemplos dentro del espacio medial chileno, para así apreciar quiénes son inmunizados y se encuentran dentro de estas "reglas higiénicas y sanitarias", en oposición al cuerpo expuesto, enfermo, sucio y en llamas que representa Pitronello.

\section{“Angelitos” vs delincuentes}

Existen varios ejemplos de coberturas noticiosas que se desarrollan en el marco de la inmunidad, de la protección del cuerpo, aislados de otro sujeto peligroso, incluso cuando este ya ha sido dañado y ha perdido sus elementos de pureza y seguridad que podrían acercarlo a ese otro expuesto y dañino. Un ejemplo es la cobertura realizada en torno al caso de las nueve estudiantes del Colegio Cumbres (establecimiento perteneciente a la influyente congregación católica Legionarios de Cristo, fundada por Marcial Maciel), quienes fallecieron en un accidente de tránsito en las cercanías de Putre, el 29 de agosto de 2008.

Los medios de comunicación, sin distinción, a diferencia de otros casos de connotación social, optaron por una cobertura mesurada, distante y respetuosa, omitiendo en los despachos televisivos planos cerrados, exacerbación de preguntas poco informativas $y$, sobre todo, abandonando una cobertura de carácter policial donde la sangre, las lágrimas y los aspectos más íntimos de las víctimas y/o victimarios, son centrales en la construcción de estos relatos noticiosos. Incluso, las víctimas fueron calificadas como "angelitos", enmarcando la tragedia en una lógica de reflexión y de trascendencia religiosa, universalizando el discurso católico propio de esa comunidad escolar particular y de esta noción de "chilenidad paradigmática", que junto con apelar, a esta estructura corporativista de la sociedad, también uno de sus ejes es esta noción católica, sobre todo asociada a grupos ultraconservadores.

En este hecho noticioso, en contraposición con otros con características potencialmente similares, como la cobertura de la muerte de los ciudadanos que se 


\section{SEe}

encontraban presos en la cárcel de San Miguel, donde sí se expusieron a las familias en toda su crudeza, llorando, lamentándose en el piso e incluso, mostrando sus cadáveres en plenas coberturas noticiosas de mediodía -como lo realizó el canal Megavisión apelando a "imágenes exclusivas"-, fue recubierta por una actitud de mesura y una especie de discurso introspectivo en los despachos televisivos y las crónicas en los diarios de los consorcios Copesa y el grupo Edwards.

Existen algunos elementos que explican este tipo de coberturas al exponer los cuerpos a nivel medial. En primer lugar, el colegio Cumbres es un establecimiento de la élite chilena, en donde estudian los hijos de importantes e influyentes políticos y empresarios del país. Este no es un dato menor. Ese mismo año, de acuerdo a los datos proporcionados por María Olivia Mönckeberg en uno de sus anexos del libro Los magnates de la prensa relacionados con la inversión publicitaria del año 2008 (el mismo de la tragedia), los 50 principales avisadores en los medios de comunicación pertenecen a importantes empresas y grupos financieros (Mönckeberg, 2009: 439), como París S.A, Falabella S.A.C.I, Banco de Chile, Agrosúper, Farmacias Ahumada o Banco Santander, cuyos ejecutivos y accionistas tienen una amplia presencia en los colegios de élite como el mencionado Cumbres.

Incluso entre las jóvenes fallecidas se encontraba la hija de Fernando Barros, abogado de Augusto Pinochet en el caso Riggs y vocero durante su detención en Londres, y la nieta de Patricia Matte (Hija de abogado, 2008) integrante de uno de los grupos económicos más poderosos del país, dueños de la CMPC, de Colbún (entidad detrás del Proyecto Energético Hidroaysén que se intenta desarrollar en la Patagonia chilena) y ella, en particular, muy influyente en temas educacionales -a favor de políticas educacionales que promuevan un fortalecimiento de la educación privada- dentro de la Alianza por Chile.

El problema no es que se deba estar a favor o no de que exista una cobertura respetuosa; este radica en que el enfoque noticioso no funciona de la misma forma para ciudadanos que provienen de distintos estratos socioeconómicos, étnicos, de género, religiosos (cabe recordar el caso del paquistaní Mohamed Saif Ur Rehman, acusado de portar trazas explosivas), etc.

El concepto de anestesia, desarrollado también por Brossat, entrega elementos para comprender este fenómeno, que viene a complementar la lógica económica y que se presenta en esos espacios que se desplazan más allá del margen de lo común, en donde el sentimentalismo de Rorty o la inmunidad democrática tampoco están presentes ni generan condiciones de seguridad.

Brossat señala que, tomando una idea de Renan, "la anestesia actúa de un modo negativo -en el sentido del "no": no a dolores inútiles, al igual que la democracia a la americana permitía descontar la desaparición de tocaciones y ocupaciones inútiles" (Brossat, 2008: 58). El autor agregará más adelante lo 


\section{SEe}

siguiente: "De una manera no explícita, no codificada pero sin embargo patente, ese derecho a escapar de dolores grandes y pequeños es percibido, en los países desarrollados, como parte integrante de la condición democrática, de la suavidad democrática. Identificaremos fácilmente aquí otra de esas fronteras invisibles que corta nuestro mundo en dos: por un lado, esas zonas donde condición anestésica y condición democrática están así estrechamente relatadas una con otra, y por otra parte, aquellas donde persiste lo inmemorial de una condición según la cual la prueba del dolor es percibida como una fatalidad" (Brossat, 2008: 60). Eso es justamente lo que ocurre con este tipo de coberturas noticiosas.

Es posible plantear que el tratamiento del dolor, en los medios, operan con estas lógicas de diferenciación, estableciendo enfoques de morbosidad, exacerbación y "fatalidad" del dolor, por un lado, y de recogimiento e introspección por el otro, dependiendo de quién es el depositario de dicho sufrimiento.

El punto está en que estas lógicas de indiferenciación no se presentan hacia toda la sociedad de forma transversal, sino que apuntan hacia sectores específicos que no se encuentran recubiertos con estas seguridades democráticas. Están en ese más allá, en ese espacio sin espacio, fuera de los principios occidentales supuestamente universales.

Ahí, al igual que los ciudadanos calcinados en la cárcel de San Miguel, entra Luciano Pitronello. Su imagen no fue protegida, resguardada. Al contrario, se exacerbó su exposición hasta límites pocas veces visto. Su cuerpo en llamas exhibido de forma reiterada opera como una especie de advertencia ante lo que podría pasar si alguien decide adscribir ese tipo de ideologías.

\section{Conclusiones}

Los comentarios generados en torno a la noticia de Luciano Pitronello, supuesto ejecutor de un fallido atentado explosivo en contra de una sede bancaria, que terminó con su cuerpo calcinado, tanto en su blog personal como en portales online de noticias como es el caso de Emol, exponen algunos elementos de una racionalidad subyacente, poco observada, dentro de ciertos integrantes de la sociedad chilena. Por cierto, no es posible determinar si es una actitud generalizada -la realización posterior de un trabajo de campo representativo de la sociedad chilena ayudaría a aclarar su grado de penetración-, pero si esboza una problemática que cabría ser mirada con mayor atención.

Epítetos como "terrorista”, “lacra” o “parásito asqueroso”, que buscan denunciar y estigmatizar una condición de "pseudo-humanidad", ponen en entredicho las nociones universalistas de los Derechos Humanos, ya que pese a ser reivindicados en la actualidad desde una mirada holista, supuestamente inclusiva, en la terminología de Richard Rorty ese margen de universalidad solo se circunscribe "a 


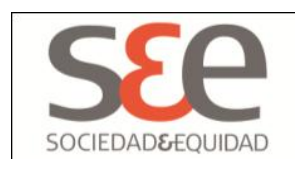

la gente como nosotros". Una expresión que ponga en duda, en este caso, al sujeto chileno paradigmático o a cualquier expresión regional y/o étnica asociada a "la gente como nosotros", tiene características potenciales de ser posicionada dentro de la mirada de una humanidad limítrofe, ajena a la supuesta racionalidad compartida y hegemónica. Es decir, susceptible de ser atacada, criticada, condenada, como ocurre con el caso de Pitronello.

Junto a este tipo de racionalidad, los medios de comunicación también operan dentro de una matriz similar. Tanto los canales de televisión como los medios escritos han exacerbado una dualización en el desarrollo de sus coberturas informativas en donde se observa, en la exposición de los cuerpos, una división entre inmunizados y expuestos. Por un lado, se encuentran los cuerpos inmunizados, que son protegidos en las coberturas informativas, sobre todo aquellos que están asociados a estructuras de poder presentes en el país. El caso del accidente ocurrido en Putre el año 2008, en donde fallecieron estudiantes del Colegio Cumbres, demuestra esta protección de cuerpos paradigmáticos, los que son tratados con respeto, distancia y mesura. Se encuentran en el polo opuesto de lo ocurrido con Pitronello. Por el otro, en cambio, se encuentran esos cuerpos expuestos, vulnerables, exhibidos sin ningún tipo de obstáculo, ya que no están recubiertos de esas seguridades propias de la democracia inmunitaria desarrollada por Brossat. Ahí está el caso de Pitronello, en el que los medios de comunicación exhibieron cómo se quemaba poco a poco en televisión y también lo que ocurrió con el incendio en la cárcel de San Miguel, donde los cuerpos calcinados de los ciudadanos reos fueron exhibidos en televisión y sus familiares fueron entrevistados y filmados, de forma reiterada y sin ningún límite.

Este problemático escenario esboza la presencia de ciudadanos que operan bajo lógicas de racionalidades antagónicas e incompatibles entre ellas. Cabría preguntarse si esta fractura va más allá de comentarios de Internet y tiene una presencia de mayor extensión en la sociedad chilena. El presente trabajo podría ser el punto inicial para estudios sobre racionalidad de mayor amplitud, relacionados con instrumentos de corte estadístico o entrevistas en profundidad a un grupo amplio de la población, que permitan sostener o refutar los planteamientos esbozados en este ensayo. Los indicios proporcionados llaman a mantener una mirada, por lo menos, de sospecha. Además, se señaló un elemento de explicación preliminar de esta fractura, puesto en discusión, relacionado con el modelo político-institucional presente en el país, establecido y legitimado en medio de una dictadura militar, en donde las torturas y las desapariciones permitieron consolidar un modelo de sociedad sin debate ni posibilidad de edificarlo dentro de márgenes democráticos.

Todo esto lleva a plantearse la siguiente pregunta a modo de reflexión final: ¿Qué tan distintos somos de los nazis, los criminales serbios, los hutus en Ruanda o los torturadores estadounidenses en Guantánamo, cuando usamos una terminología y 


\section{SEe}

racionalidad similar para condenar y estigmatizar a ciertos grupos de la ciudadanía diferentes al supuesto paradigma civilizatorio, con el mismo nivel de violencia, rabia y crueldad que emplearon estos como preámbulo para cometer sus crímenes y genocidios?

Pareciera que no estamos tan lejos de ellos. Es cierto que actualmente no se están estableciendo en Chile políticas sistemáticas de exterminio ni de tortura, pero ese tipo de lenguaje y esa racionalidad subyacente, recubierta de desprecio y estigmatización, en muchos casos, empezó todo. Por ejemplo, "Radio Televisión Libre de las Mil Colinas” en Ruanda, con su propaganda anti-tutsi, abrió las puertas a uno de los genocidios más brutales de la historia moderna.

Como sociedad, lo mínimo que corresponde es que mantengamos una postura de alerta. Hay varios elementos que entregan indicios de que no estamos resguardados ante este tipo de situaciones.

\section{Referencias Bibliográficas}

Brossat, Alain (2008). La democracia inmunitaria. Santiago: Palinodia.

Comisión Nacional sobre Prisión Política y Tortura (2004). Prólogo. Recuperado el 3 de julio de 2011. Disponible desde Internet en<http: //www.comisionvalech.gov.cl/informeValech/prologo.pdf>

Escritos de bohemia (2005). Ayudar. Recuperado el 5 de julio de 2011. Disponible desde Internet en <http://bohemia.bitacoras.com/archivos/2005/12/23/ayudar>

Escritos de bohemia (2005). Protestas. Recuperado el 5 de julio de 2011. Disponible desde Internet en <http://bohemia.bitacoras.com/archivos/2005/12/24/protestas>

Grez, Sergio (2007). Los anarquistas y el movimiento obrero. La alborada de "la Idea" en Chile, 1893-1915.Santiago: Lom.

Klein, Naomi (2007). La doctrina del shock. Barcelona: Paidós.

Mönckeberg, María Olivia (2009). Los magnates de la prensa. Concentración de los medios de comunicación en Chile. Santiago: Debate. 


\section{SSe}

Rorty, Richard (1993). Derechos humanos, racionalidad y sentimentalismo. The Yale Review, volumen 81, número 3.

Stabili, María Rosaria (2003). El sentimiento aristocrático. Élites chilenas frente al espejo (1860-1960). Santiago: Editorial Andrés Bello y Centro de Investigaciones Diego Barros Arana

\section{Archivo de Prensa:}

Cómo orientar a hijos anarquistas y rebeldes. Recuperado el 9 de julio de 2011. Disponible en Internet en <http://www.emol.com/tendenciasymujer/Noticias/2011/07/08/21418/Comoorientar-a-hijos-anarquistas-y-rebeldes.aspx>

Mujer embarazada detenida por error: "Me decían que me iban a quitar a mi hijo cuando naciera". Recuperado el 3 de julio de 2011. Disponible desde Internet en <http://latercera.com/contenido/680_92981_9.shtml>

Caso bombas: juez sobresee a okupa y acusa a fiscalía de hacer "sociología barata". Recuperado el 5 de julio de 2011. Disponible desde Internet en <http://diario.latercera.com/2011/05/04/01/contenido/pais/31-67850-9-casobombas-juez-sobresee-a-okupa-y-acusa-a-fiscalia-de-hacer-sociologia-barata.shtml>

Embarazada de seis meses fue detenida por tres asaltos en el sector oriente. Recuperado el 3 de julio de 2011. Disponible desde Internet en <http://www.emol.com/noticias/nacional/detalle/detallenoticias.asp?idnoticia=339 583>

Hija de abogado Fernando Barros y nieta de Patricia Matte están entre víctimas de fatal accidente (2008). Recuperado el 10 de julio de 2011. Disponible desde Internet en <http://www.latercera.cl/contenido/25_45108_9.shtml>

Joven queda gravemente herido al intentar poner una bomba en banco de Santiago. Recuperado el 9 de julio 2011. Disponible desde Internet 
Rev. Sociedad \& Equidad № 3, Enero de 2012. Pp. 152-171

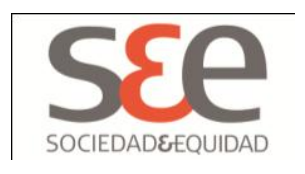

de <http://www.emol.com/noticias/nacional/detalle/detallenoticias.asp?idnoticia= 484821> 